Molecular Genetic Pathology 



\section{Liang Cheng}

David Y. Zhang

John N. Eble

Editors

\section{Molecular Genetic Pathology}

Second Edition

글 Springer Reference 


\section{Editors}

Liang Cheng

Department of Pathology and Laboratory Medicine

Indiana University School of Medicine

Indianapolis, IN, USA

David Y. Zhang

Department of Pathology

Mount Sinai School of Medicine

New York, NY, USA

John N. Eble

Department of Pathology and Laboratory Medicine

Indiana University School of Medicine

Indianapolis, IN, USA

ISBN 978-1-4614-4799-3

ISBN 978-1-4614-4800-6 (eBook)

ISBN 978-1-4614-4801-3 (print and electronic bundle)

DOI 10.1007/978-1-4614-4800-6

Springer New York Heidelberg Dordrecht London

Library of Congress Control Number: 2012952466

(C) Springer Science+Business Media New York 2013

This work is subject to copyright. All rights are reserved by the Publisher, whether the whole or part of the material is concerned, specifically the rights of translation, reprinting, reuse of illustrations, recitation, broadcasting, reproduction on microfilms or in any other physical way, and transmission or information storage and retrieval, electronic adaptation, computer software, or by similar or dissimilar methodology now known or hereafter developed. Exempted from this legal reservation are brief excerpts in connection with reviews or scholarly analysis or material supplied specifically for the purpose of being entered and executed on a computer system, for exclusive use by the purchaser of the work. Duplication of this publication or parts thereof is permitted only under the provisions of the Copyright Law of the Publisher's location, in its current version, and permission for use must always be obtained from Springer. Permissions for use may be obtained through RightsLink at the Copyright Clearance Center. Violations are liable to prosecution under the respective Copyright Law.

The use of general descriptive names, registered names, trademarks, service marks, etc. in this publication does not imply, even in the absence of a specific statement, that such names are exempt from the relevant protective laws and regulations and therefore free for general use.

While the advice and information in this book are believed to be true and accurate at the date of publication, neither the authors nor the editors nor the publisher can accept any legal responsibility for any errors or omissions that may be made. The publisher makes no warranty, express or implied, with respect to the material contained herein.

Printed on acid-free paper

Springer is part of Springer Science+Business Media (www.springer.com) 


\section{Preface}

Since the first edition of this textbook, the field of molecular genetic pathology has expanded exponentially. The advent of complete cancer genome sequencing, emerging tests for identification of infectious agents, new diagnostic molecular tests, and biomarkers for targeted therapy have demonstrated the importance of molecular tools both in patient care and in the practice of pathology. Furthermore, the development of many new technologies, including various microarray platforms, nanotechnology, and nextgeneration sequencing, has revolutionized the practice of molecular genetic pathology. The rapid growth of this field has led to an expansion of knowledge of molecular processes and many more clinical applications in molecular diagnostics. Thus, we recognize the need to update this textbook and hope that the second edition of the Molecular Genetic Pathology will continue to be the best available "quick reference" for pathologists, oncologists, geneticists, primary care physicians, and other medical professionals with an interest in this specialty. In addition, it is our continued belief that a concise overview of the field of molecular genetic pathology, emphasizing its clinical applications, will help not only practicing physicians, but also those in training, including residents and fellows in various disciplines.

The first edition of the Molecular Genetic Pathology has received much positive feedback from its readers. The two main features of the book commended by readers are the concise bullet-point format and the many useful charts and figures. These remain in the second edition. It should also be noted that over 100 leading experts have contributed to this new edition. The second edition of the Molecular Genetic Pathology is composed of seven sections, and 46 chapters. Sections 1 and 2 explore the basic principles and methodology of molecular genetic techniques. Sections 3 through 7 focus on disease-based information, including genetic disorders, molecular microbiology, hematologic malignancy assessment, diagnosis of hematological disorders, specialized applications of molecular tools, and management of the molecular laboratory.

Assembling this diverse textbook has truly been a team effort, cutting across many traditional specialty boundaries. We are most grateful for all the contributors who have made this project possible and to the readers of the first edition who provided much valuable feedback. Our special thanks go to Ms. Tracey Bender, without whose outstanding work this textbook would have been an impossible achievement. We would like to thank Mr. Ryan P. Christy from the Multimedia Education Division of the 
Department of Pathology at Indiana University, who has edited the illustrations for the handbook. We would also like to thank the staff at Springer, including Mr. Richard Hruska, Ms. Maureen Alexander, Ms. Neha Thapa, Ms. Saranya Jayakumar, and other colleagues for their assistance in the development and editing of this textbook.

January 2013

Liang Cheng, MD

David Y. Zhang, MD, PhD

John N. Eble, MD 


\section{Biography}

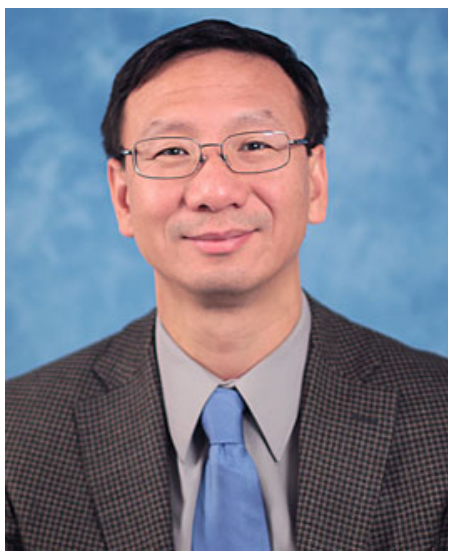

Liang Cheng, MD, Professor of Pathology and Urology, Director of Molecular Pathology Laboratory, Chief of Genitourinary Pathology Division, Director, Fellowship in Urologic Pathology, Indiana University School of Medicine, Indianapolis, IN, USA

Dr. Liang Cheng is professor of pathology and urology at the Indiana University School of Medicine, Indianapolis, Indiana, USA. Currently, he is the chief of the Genitourinary Pathology Service, director of the Urologic Pathology Fellowship Program, and director of Molecular Diagnostics and Molecular Pathology Laboratories. Dr. Cheng is board certified in molecular genetic pathology and anatomic and clinical pathology by the American Board of Pathology. He graduated from Beijing Medical University, China. Dr. Cheng completed his pathology residency at Case Western Reserve University, Cleveland, Ohio, and his fellowship at the Mayo Clinic, Rochester, Minnesota, in 1998. Dr. Cheng has received numerous prestigious awards including the Stowell-Orbison Award from the United States and Canadian Academy of Pathology (USCAP) and the Koss Medal Award from the International Society of Urological Pathology (ISUP). In 2006, he was the Arthur Purdy Stout Prize recipient from the Arthur Purdy Stout Society of Surgical Pathologists in recognition of outstanding contributions to the field of surgical pathology by a surgical pathologist less than 45 years old. Dr. Cheng has published more than 500 peer-reviewed articles in 
high-impact scientific journals. He was also the author of over 60 book chapters and several books. Currently, he is an active member of over 30 editorial boards. His research focuses on molecular genetics and biological predictors of genitourinary cancers.

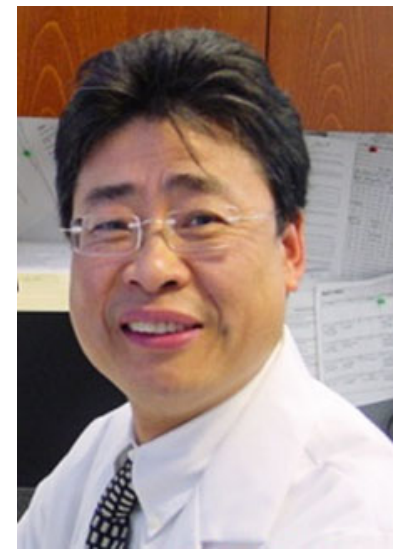

David Y. Zhang, MD, PhD, MPH, Director, Molecular Pathology Laboratory, Professor, Departments of Pathology and Oncological Sciences, Mount Sinai School of Medicine, New York, NY, USA

David Y. Zhang MD, Ph.D., MPH, is the director of the Molecular Pathology Division. He obtained his MD from Norman Bethune School of Medicine of Jilin University, Ph.D. from New York University School of Medicine, and MPH from Mount Sinai School of Medicine. He subsequently completed his residency training in anatomic and clinical pathology as well as fellowship training in cytopathology and clinical microbiology at Mount Sinai School of Medicine, New York. He also completed second residency in preventive medicine (occupational medicine) at the Selikoff Center, Mount Sinai School of Medicine. He is licensed to practice medicine in New York and New Jersey and certified in anatomic and clinical pathology, cytopathology, molecular genetic pathology by the American Boards of Pathology and Medical Genetics as well as in preventive medicine by the American Board of Preventive Medicine. He currently practices surgical pathology, cytopathology, and molecular pathology with a strong interest in solid tumor pathology. His major research interest is to develop genomic and proteomic technologies for biomarker discovery and molecular diagnosis. He currently holds more than 10 US and international patents and has published more than 50 scientific papers in major peer-reviewed journals and more than 10 book chapters. 


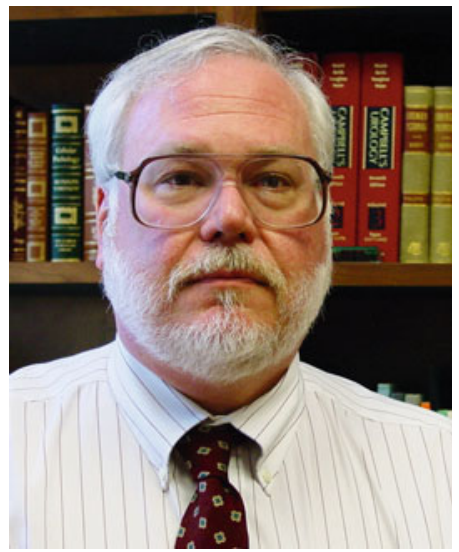

John N. Eble MD, MBA, FRCPA, Nordschow Professor and Chairman, Department of Pathology and Laboratory Medicine, Indiana University School of Medicine, Indianapolis, IN, USA

Dr. John Eble obtained his medical degree from the Indiana University School of Medicine, where he also took his residency in anatomic and clinical pathology. Following residency, he joined the faculty of the Department of Pathology and Laboratory Medicine of Indiana University and became the head of the clinical laboratories at the Roudebush VA Medical Center at the Indiana University Medical Center. While at the VA, he established the first diagnostic molecular pathology laboratory in Indiana. A few years later, he attended the Indiana University Graduate School of Business and received an MBA degree in 1990. Dr. Eble continued as the VA chief of service until 2000. In 1998, Dr. Eble was appointed chairman of the Department of Pathology and Laboratory Medicine of the Indiana University School of Medicine and chief pathologist of Indiana University Health. In addition to his leadership activities, Dr. Eble currently signs out the urologic surgical pathology cases of Indiana University Health one week a month. While these events were developing, Dr. Eble used the rich clinical material of the VA Medical Center and IU Health as a foundation upon which to study urologic pathology. He has published more than 225 peer-reviewed papers, more than 30 book chapters, and 3 books devoted to diseases of the organs of the urinary tract and male genital system. With Jonathan Epstein, Guido Sauter, and Isabell Sesterhenn, he edited the 2004 World Health Organization "blue book" World Health Organization Classification of Tumours. Pathology and Genetics of Tumours of the Urinary System and Male Genital Organs.

Dr. Eble has shared his knowledge of urologic pathology with thousands of pathologists and urologists around the world. He served on the faculty of the pathology review course of the American Urologic Association from 1991 to 2000. He gave a course on renal neoplasia (with David Grignon) for the American Society of Clinical Pathologists from 2005 to 2008, directed their $73^{\text {rd }}$ annual Slide Seminar on Anatomic Pathology in 2005, and is presently on the faculty of their annual course Contemporary Issues in Urologic Pathology. He served on the faculty of the annual Harvard course Urologic 
Surgical Pathology for the Practicing Pathologist since its inception in 1997 to 2011. He became active in the International Society for Urologic Pathology at the time it was founded in 1990. He served as a councillor from 1991 to 1995, as its treasurer from 1995 to 2001, and its president-elect and president from 2001 to 2005. The Society awarded him the Leopold Koss Medal for Distinguished Service in 2003. With David Bostwick, Dr. Eble gave his first short course for the USCAP, Incipient Neoplasia in Diagnostic Urologic Pathology, from 1994 to 1998. This was followed by Tumors of the Kidneys and Ureters (with Stephan Störkel) from 1997 to 2000. Next was Renal Neoplasia: Diagnostic Problems and Newly Recognized Entities (with Holger Moch) from 2005 to 2008. Most recently, he has given Handling and Reporting of Tumor-containing Specimens in Urologic Pathology (with David Grignon). In 2008, he directed the Long Course, Tumors of the Kidneys and Urinary Bladder with David Grignon. When Dr. Mills announced he would be stepping down as editor of Modern Pathology, Dr. Eble had been editing the quarterly Journal of Urologic Pathology for 3 years and was looking for an opportunity to edit a major monthly pathology journal and so he applied for the position. The Academy selected him and he became the fourth editor of Modern Pathology in 2000. The Academy honored Dr. Eble with the F.K. Mostofi Award for distinguished service in 2010. The Royal College of Pathologists of Australasia made Dr. Eble an honorary fellow in 2001. 


\section{Contents}

\section{Volume 1}

\section{Section 1 Basic Principles in Molecular Genetic}

Pathology .................. 1

1 Clinical Molecular Biology: Principles $\ldots \ldots \ldots \ldots \ldots \ldots$

Shaobo Zhang, Darrell D. Davidson, and Liang Cheng

2 Clinical Cytogenetics: Principles $\ldots \ldots \ldots \ldots \ldots \ldots \ldots \quad 43$

Stuart Schwartz

3 Conceptual Evolution in Cancer Biology . . . . . . . . . . . . 77

Shaobo Zhang, Darrell D. Davidson, Rodolfo Montironi,

Antonio Lopez-Beltran, Gregory T. MacLennan, and

Liang Cheng

4 Genetic Inheritance and Population Genetics $\ldots \ldots \ldots \ldots 111$

Tatiana Foroud and Daniel L. Koller

5 Clonality Analysis and Tumor of Unknown Primary:

Applications in Modern Oncology and

Surgical Pathology

Liang Cheng, Shaobo Zhang, Federico A. Monzon,

Timothy D. Jones, and John N. Eble

6 Modern Immunohistochemistry in Targeted Therapy ....

Allen M. Gown

7 Systems Pathology

José Costa and Michael J. Donovan

\section{Section 2 Methodology in Molecular Genetic} Pathology

8 Diagnostic Methodology and Technology in Molecular

Genetic Pathology

Josephine Wu, Fei Ye, Miao Cui, Robert Shibata, Ruliang Xu,

Liang Cheng, and David Y. Zhang 
9 Clinical Flow Cytometry in Molecular Genetic

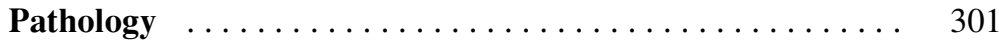

Magdalena Czader

10 Clinical Genomics in Oncology $\ldots \ldots \ldots \ldots \ldots \ldots \ldots$

Hugo M. Horlings, Thalia A. Farazi, and Marc J. van deVijver

11 Clinical Proteomics in Molecular Genetic Pathology . . . . 369

David H. Geho, Virgina Espina, Lance A. Liotta,

Emanuel F. Petricoin, and Julia D. Wulfkuhle

12 Nanotechnology in Molecular Diagnostics

Andrew N. Young and Brad A. Kairdolf

13 Gene Therapy: Vector Technology and Clinical

Applications

Sunyong Tang and Kenneth Cornetta

14 Instrumentation for Molecular Testing

Jordan Laser, Miao Cui, Bruce E. Petersen, Fei Ye, and

David Y. Zhang

15 Tissue Microarrays and Biomarker Validation in

Molecular Diagnostics ....................

Martina Storz and Holger Moch

16 Laser Capture Microdissection in Molecular

Diagnostics . . . . . . . . . . . . .

Liang Cheng, Shaobo Zhang, Darrell D. Davidson,

Matthew Kuhar, Mingsheng Wang, Sean R. Williamson,

David Y. Zhang, and Gregory T. MacLennan

17 Human Tissue Biorepository $\ldots \ldots \ldots \ldots \ldots \ldots \ldots$

William E. Grizzle, Katherine C. Sexton, and Walter C. Bell

18 Pathology Informatics . . . . . . . . . . . . . . . . . . 499

Roy E. Lee, Long Phi Le, and John Gilbertson

Section 3 Genetic Disorders

19 Prenatal Cytogenetic and Cytogenomic Diagnosis $\ldots \ldots \ldots 517$

Ninette Cohen and Lisa Edelmann

20 Molecular Medical Genetics

Lisa Edelmann, Stuart Scott, Liu Liu, and Ruth Kornreich

\section{Volume 2}

21 Biochemical Genetics and Inborn Errors of Metabolism ... 561 Chunli Yu, Melissa P. Wasserstein, and George A. Diaz 
22 Molecular Genetics of Congenital Heart Disease

Abigail S. Carey and Bruce D. Gelb

23 Familial Cancer Syndrome

Beth T. Harrison, Rodolfo Montironi, Antonio Lopez-Beltran,

Michelle P. Elieff, and Liang Cheng

24 Genetic Counseling

Kimberly A. Quaid and Lisa J. Cushman

Section 4 Molecular Microbiology

25 Molecular Virology

Fei Ye, Miao Cui, Rame H. Khasawneh, Robert Shibata, Josephine Wu, Mona Sharaan, and David Y. Zhang

26 Molecular Bacteriology and Mycobacteriology

Jeong Hwan Shin, Mona Sharaan, Josephine Wu, Miao Cui, David Y. Zhang, and Yi-Wei Tang

27 Molecular Parasitology and Mycology

Vincent J. LaBombardi and Wei Wang

28 Molecular Microbiology in Transplantation

Adnan A. Alatoom and Robin Patel

29 Molecular Microbiology Epidemiology

Miao Cui, Fei Ye, and David Y. Zhang

Section 5 Hematologic Malignancies ........

30 Immunoglobulin and T Cell Receptor Gene

Rearrangement: Principle

Jeffrey E. Miller

31 Lymphoblastic Leukemia and Lymphoma: Molecular

Diagnostics

Dan Jones and Zeqiu J. Han

32 Myeloid Neoplasms: Molecular Diagnostics

C. Cameron Yin and Dan Jones

33 Lymphoid Malignancies: Molecular Diagnostics

Vasiliki Leventaki and Francisco Vega

34 Myeloproliferative Neoplasms and Myelodysplastic

Syndromes: Molecular Diagnostics

Gerlinde Wernig and Daniel A. Arber

35 Lymphoproliferative Disorders: Molecular Diagnostics ... 


\section{Section 6 Hematological Disorders and Specialized}

Applications ............... 953

36 Molecular Testing for Coagulation Abnormalities ...... 955

Veshana Ramiah and Thomas L. Ortel

37 Molecular Hemoglobinopathies . . . . . . . . . . . . . . . 975

Tina Y. Fodrie, Shaobo Zhang, Mina Patel,

Jodi A. Parks, and Liang Cheng

38 HLA System and Transfusion Medicine: Molecular

Approach

S. Yoon Choo

39 Clinical Pharmacogenomics

Catalina López-Correa and Lawrence M. Gelbert

40 Molecular Forensic Pathology

Stephen R. Dlouhy and P. Michael Conneally

41 Specimen Identification and Bone Marrow Engraftment

Analysis

Loren Joseph

42 Circulating Tumor Cells: Liquid Biopsy for Molecular

Pathology

Jeffrey S. Ross

\section{Section 7 Laboratory Management in Molecular} Genetic Pathology ............. 1081

43 Molecular Testing: Ethical and Legal Issues f . . . . . . . 1083 Kimberly A. Quaid

44 Molecular Testing: Regulatory Issues . . . . . . . . . . . . 1091 Frank S. Ong, Wayne W. Grody, and Kingshuk Das

45 Molecular Pathology Reporting ... . . . . . . . . . . . . . . . . 1109 Stacey S. O'Neill and Margaret L. Gulley

46 Laboratory Management: Quality Assurance and

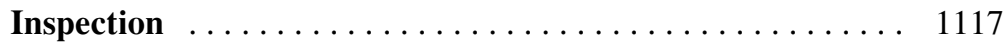

Kristin M. Post and Liang Cheng

Index 


\section{Contributors}

Adnan A. Alatoom, MD, PhD, ABMM, FCAP Assistant Professor of Clinical Pathology and Microbiology, Department of Pathology, University of Texas Southwestern Medical Center, Dallas, TX, USA

Daniel A. Arber, MD Professor - Med Center Line, Pathology, Department of Pathology, Stanford University School of Medicine, Stanford, CA, USA

William C. Bell, MD Associate Professor, Department Anatomic Pathology, University of Alabama School of Medicine, Birmingham, AL, USA

Abigail S. Carey, MD Department of Pediatrics, Mount Sinai School of Medicine, New York, NY, USA

Liang Cheng, MD Professor of Pathology and Urology, Director of Molecular Pathology Laboratory, Chief of Genitourinary Pathology Division, Director, Fellowship in Urologic Pathology, Indiana University School of Medicine, Indianapolis, IN, USA

S. Yoon Choo, MD Associate Professor of Pathology and Medicine, Director of Immunogenetics and Associate Medical Director of Transfusion Medicine, Mount Sinai School of Medicine, New York, NY, USA

Ninette Cohen, PhD Assistant Professor, Mount Sinai School of Medicine, Genetic and Genomic Sciences, New York, NY, USA

P. Michael Conneally, PhD Professor of Medical and Molecular Genetics, Department of Medical and Molecular Genetics, Indiana University School of Medicine, Indianapolis, IN, USA

Kenneth Cornetta, MD Joe C. Christian Professor and Chair, Department of Medical and Molecular Genetics, Indiana University School of Medicine, Indianapolis, IN, USA

José Costa, MD Professor of Pathology and Medicine, Vice Chairman, Department of Pathology, Yale University School of Medicine, New Haven, CT, USA

Miao Cui, MD Associate Researcher of Pathology, Department of Pathology, Mount Sinai School of Medicine, New York, NY, USA

Lisa J. Cushman, PhD, CGC Hayes, Inc., Landsale, PA, USA 
Magdalena Czader, MD, PhD Director, Division of Hematopathology, Director, Clinical Flow Cytometry Laboratory, Department of Pathology and Laboratory Medicine, Indiana University School of Medicine, Indianapolis, IN, USA

Kingshuk Das, MD Assistant Clinical Professor, Department of Pathology and Laboratory Medicine, UCLA David Geffen School of Medicine, Los Angeles, CA, USA

Darrell D. Davidson, MD, PhD Clinical Assistant Professor, Indiana University School of Medicine, IU Health Pathology Laboratory, Indianapolis, IN, USA

George A. Diaz, MD, PhD Associate Professor, Department of Genetics \& Genomic Sciences, Mount Sinai School of Medicine, New York, NY, USA

Stephen R. Dlouhy, PhD Associate Research Professor, Department of Medical and Molecular Genetics, Indiana University School of Medicine, Indianapolis, IN, USA

Michael J. Donovan, PhD, MD Professor of Pathology, Director of Experimental Pathology, Mount Sinai School of Medicine, New York, NY, USA

John N. Eble, MD, MBA, FRCPA Nordschow Professor and Chairman, Department of Pathology and Laboratory Medicine, Indiana University School of Medicine, Indianapolis, IN, USA

Lisa Edelmann, PhD Associate Professor, Department of Genetic and Genomic Sciences, Mount Sinai School of Medicine, New York, NY, USA

Michelle Elieff, MD Forensic Pathologist, Sparrow Forensic Pathology Services, Lansing, MI, USA

Virgina Espina, MS Research Assistant Professor, George Mason University, Center for Applied Proteomics and Molecular Medicine, Manassas, VA, USA

Thalia A. Farazi, MD, PhD Instructor in Clinical investigation, Howard Hughes Medical Institute, Laboratory of RNA Molecular Biology, The Rockefeller University, New York, NY, USA

Tina Y. Fodrie, MT, MP(ASCP) Laboratory Manager, Translational Research and Clinical Coordinator, Laboratory for Personalized Molecular Medicine, San Diego, California, USA

Tatiana Foroud, PhD Chancellor's Professor, P. Michael Conneally Professor of Medical and Molecular Genetics, Director, Division of Hereditary Genomics, Department of Medical and Molecular Genetics, Indiana University School of Medicine, Indianapolis, IN, USA

David H. Geho, MD, PhD Associate Director, Imaging, Merck and Company, Inc., West Point, PA, USA 
Bruce D. Gelb, MD Director, Child Health and Development Institute, New York, NY, USA; Professor of Pediatrics, Cardiology, Professor of Genetics \& Genomic Sciences, Mount Sinai School of Medicine, New York, NY, USA

Lawrence Gelbert, PhD Managing Member at LMG PharmaTech, LLC, Indianapolis, IN, USA; Adjunct Professor of Pediatrics, Herman B Wells Center for Pediatric Research, Indiana University School of Medicine, Indianapolis, IN, USA

John Gilbertson, MD Associate Professor of Pathology, Harvard Medical School, Department of Pathology, The Massachusetts General Hospital, Boston, MA, USA

Allen M. Gown, MD Medical Director and Chief Pathologist, PhenoPath Laboratories, Seattle, WA, USA; Clinical Professor of Pathology, University of British Columbia, Vancouver, BC, Canada

Timothy C. Greiner, MD Professor, Department of Pathology and Microbiology, University of Nebraska Medical Center, Omaha, NE, USA

William E. Grizzle, MD, PhD Professor of Pathology, Head, Program for Translational Research in Neoplasia, Director, Tissue Procurement and Banking Facility, Senior Scientist, UAB Comprehensive Cancer Center; Center for Aging; Metabolic Bone Disease Research Center, Senior Editor, Clinical Cancer Research, Birmingham, AL, USA

Wayne W. Grody, MD, PhD Professor, Divisions of Medical Genetics and Molecular Pathology, Departments of Pathology and Laboratory Medicine, Pediatrics, and Human Genetics, UCLA School of Medicine, Los Angeles, CA, USA

Margaret L. Gulley, MD Professor of Pathology, University of North Carolina, Chapel Hill, NC, USA

Zeqiu J. Han, MD Department of Pathology, Quest Diagnostics Nichols Institute, Chantilly, VA, USA

Beth T. Harrison, MD Department of Pathology, NYU Langone Medical Center, New York, NY, USA

Hugo M. Horlings, MD, PhD Pathologist, Academic Medical Center, Amsterdam, The Netherlands

Dan Jones, MD, PhD Medical Director, Cancer Diagnostics Services, Quest Diagnostics Nichols Institute, Chantilly, VA, USA

Timothy D. Jones, MD Staff Pathologist, East Louisville Pathologists, PSC, Louisville, KY, USA

Loren Joseph, MD Director, Molecular Pathology Laboratory, Department of Pathology, University of Chicago Medical Center, Chicago, IL, USA 
Brad A. Kairdolf, PhD Postdoctoral Fellow, Department of Biomedical Engineering, Emory University and Georgia Institute of Technology, Atlanta, GA, USA

Rame H. Khasawneh, MD Molecular Genetic Pathology Fellow, Department of Pathology, Mount Sinai School of Medicine, New York, NY, USA

Daniel L. Koller, PhD Assistant Research Professor, Department of Medical and Molecular Genetics, Indiana University School of Medicine, Indianapolis, IN, USA

Ruth Kornreich, PhD Research Assistant Professor of Human Genetics, Co-Director Genetic Testing Laboratory, Department of Human Genetics, Mount Sinai School of Medicine and the Mount Sinai Medical Center, New York, NY, USA

Matthew Kuhar, MD Associate Dermatopathologist, StrataDx \& Strata Pathology Services, One Cranberry Hill, Lexington, MA, USA

Vincent J. LaBombardi, PhD Chief of Microbiology, New York Hospital-Queens, Flushing, NY, USA

Jordan Laser, MD Assistant Professor of Pathology, Director of Molecular Pathology, Department of Pathology and Laboratory Medicine, North Shore / Long Island Jewish Health System, Manhasset, NY, USA

Long Phi Le, MD, PhD Assistant Professor of Pathology, Harvard Medical School, Department of Pathology, The Massachusetts General Hospital, Boston, MA, USA

Roy E. Lee, MD Associate Medical Director for the Center of Pathology Informatics, Pathology and Laboratory Medicine Institute, The Cleveland Clinic, Cleveland, $\mathrm{OH}$, USA

Vasiliki Leventaki, MD Hematopathology Fellow, Department of Hematopathology, The University of Texas MD Anderson Cancer Center, Houston, TX, USA

Lance A. Liotta, MD, PhD Professor, George Mason University, Center for Applied Proteomics and Molecular Medicine, Manassas, VA, USA

Antonio Lopez-Beltran, MD, PhD Professor of Anatomic Pathology, Unit of Anatomic Pathology, Department of Surgery, Cordoba University School of Medicine, Cordoba, Spain

Catalina López-Correa, MD, PhD Vice-présidente, Affaires scientifiques/ CSO, Génome Québec, Montréal (Québec)

Liu Liu, PhD, FACMG Associate Lab Director, Assistant Professor, Cancer Genetics Laboratory, Baylor College of Medicine, Houston, TX, USA

Gregory T. MacLennan, MD Professor of Pathology, Director, Anatomic Pathology, Case Western Reserve University, Cleveland, OH, USA 
Jeffrey E. Miller, PhD Chief Scientific \& Chief Executive Officer of Invivoscribe Technologies, Inc, and the Laboratory for Personalized Molecular Medicine, LabPMM, San Diego, CA, USA

Holger Moch, MD Professor and Chairman, Institute of Surgical Pathology, Department Pathology, University Hospital Zürich, Zürich, Switzerland

Rodolfo Montironi, MD, FRCPath Professor of Pathology, Institute of Pathological Anatomy and Histopathology, Polytechnic University of the Marche Region (Ancona), School of Medicine, United Hospitals, Ancona, Italy

Federico Monzon, MD Associate Professor, Director of Molecular Pathology, Cancer Genetics Laboratory at Baylor College of Medicine, Departments of Pathology \& Immunology and Molecular \& Human Genetics at Baylor College of Medicine, Houston, TX, USA

Stacey S. O'Neill, MD, PhD Molecular Genetic Pathology Fellow, University of North Carolina, Chapel Hill, NC, USA

Frank S. Ong, MD Department of Pathology and Laboratory Medicine, Cedars-Sinai Medical Center, Los Angeles, CA, USA

Thomas L. Ortel, MD, PhD Professor of Medicine and Pathology, Hemostasis and Thrombosis Center, Duke University Medical Center, Durham, NC, USA

Jodi A. Parks, MD Department of Pathology and Laboratory Medicine, Indiana University School of Medicine, Indianapolis, IN, USA

Mina Patel, MT, MP(ASCP) Supervisor, Molecular Pathology Laboratory, Roudebush VA Medical Center, Indianapolis, IN, USA

Robin Patel, MD(CM), FRCP(C), D(ABMM), FIDSA, FACP, F(AAM)

Professor of Microbiology and Medicine, Chair, Division of Clinical Microbiology, Consultant, Divisions of Clinical Microbiology and Infectious Diseases, Mayo Clinic, Rochester, MN, USA

Bruce E. Petersen, MD Assistant Professor, Pathology and Medicine, Mount Sinai School of Medicine, New York, NY, USA

Emanuel F. Petricoin, PhD Professor, George Mason University, Center for Applied Proteomics and Molecular Medicine, Manassas, VA, USA

Kristin M. Post, MT Department of Pathology and Laboratory Medicine, Indiana University School of Medicine, IU Health Pathology Laboratory, Indianapolis, IN, USA

Kimberly A. Quaid, PhD Professor of Medical and Molecular Genetics, Indiana University School of Medicine, Faculty Investigator, Indiana University Center for Bioethics, Indianapolis, IN, USA

Veshana Ramiah, MD Danville Regional Medical Center, Danville Hematology and Oncology, Danville, VA, USA 
Jeffrey S. Ross, MD Cyrus Strong Merrill Professor and Chair, Department of Pathology and Laboratory Medicine, Albany Medical College, Albany, NY, USA; Medical Director, Foundation Medicine, Inc., Cambridge, MA, USA

Stuart Schwartz, PhD, FACMG Strategic Director, Cytogenetics, Cytogenetics Laboratory, Center for Molecular Biology and Pathology, Laboratory Corporation of America, Research Triangle Park, NC, USA

Stuart Scott, PhD Research Assistant Professor of Human Genetics, Department of Human Genetics, Mount Sinai School of Medicine and the Mount Sinai Medical Center, New York, NY, USA

Katherine C. Sexton, MBA Assistant Director, University of Alabama at Birmingham, Tissue Collection and Banking Facility, Southern Division, Cooperative Human Tissue Network, Birmingham, AL, USA

Mona Sharaan, MD Molecular Pathology Laboratory, Department of Pathology, Mount Sinai School of Medicine, New York, NY, USA

Robert Shibata, MD Molecular Genetic Pathology Fellow, Department of Pathology, Mount Sinai School of Medicine, New York, NY, USA

Jeong Hwan Shin, MD, PhD Associate Professor, Department of Laboratory Medicine, Inje University College of Medicine, Busan, South Korea

Martina Storz, MD Director of TMA Core Facility, Institute of Surgical Pathology, Department Pathology, University Hospital Zürich, Zürich, Switzerland

Sunyong Tang, PhD Indiana University Vector Production Facility, Department of Medical and Molecular Genetics, Indiana University School of Medicine, Indianapolis, IN, USA

Yi-Wei Tang, MD, PhD, F(AAM), FIDSA Chief of Clinical Microbiology Service, Memorial Sloan-Kettering Cancer Center, Professor of Laboratory Medicine and Pathology, Cornell University Weil College of Medicine, New York, NY, USA

Marc J. van de Vijver, MD, PhD Head, Division of Diagnostic Oncology, NKI, Amsterdam; Head, Department of Pathology, NKI, Amsterdam; Pathologist, Department of Pathology, Leiden University Medical Center, The Netherlands; Professor of Pathology, Department of Pathology, The Netherlands; Cancer Institute/Antoni van Leeuwenhoek Hospital, Amsterdam, Netherlands

Francisco Vega, MD, PhD Associate Professor and Lymphoma Section Head, Department of Hematopathology, The University of Texas MD Anderson Cancer Center, Houston, TX, USA

Mingsheng Wang, MD Associate Scientist, Department of Pathology and Laboratory Medicine, Indiana University School of Medicine, Indianapolis, IN, USA 
Wei Wang, PhD Research Associate, Mount Sinai Medical Center, New York, NY, USA

Melissa P. Wasserstein, MD Associate Professor, Mount Sinai School of Medicine, New York, NY, USA

Gerlinde Wernig, MD Department of Pathology, Stanford University School of Medicine, Stanford Hospital and Clinics, Stanford, CA, USA

Sean R. Williamson, MD Department of Pathology and Laboratory Medicine, Indiana University School of Medicine, Indianapolis, IN, USA

Josephine Wu, DDS, CLSP(MB), CLDIR Assistant Professor of Pathology, Mount Sinai School of Medicine, New York, NY, USA

Julia D. Wulfkuhle, PhD Professor, George Mason University, Center for Applied Proteomics and Molecular Medicine, Manassas, VA, USA

Ruliang Xu, MD, PhD Associate Professor of Pathology, Director of Molecular Pathology, Director of Gastrointestinal and Liver Pathology, Department of Pathology, New York University Langone Medical Center, New York, NY, USA

Fei Ye, PhD Assistant Professor of Pathology, Assistant Director of Molecular Pathology, Department of Pathology, Mount Sinai School of Medicine, New York, NY, USA

C. Cameron Yin, MD, PhD Associate Professor, Department of Hematopathology, UT MD Anderson Cancer Center, Houston, TX, USA

Andrew N. Young, MD, $\mathrm{PhD}$ Associate Professor, Department of Pathology \& Laboratory Medicine, Emory University School of Medicine, Laboratory Director, Grady Health System, Atlanta, GA, USA

Chunli Yu, MD Associate Professor, Department of Genetics \& Genomic Sciences and Pediatrics, Mount Sinai School of Medicine, New York, NY, USA

David Y. Zhang, MD, PhD, MPH Professor of Pathology, Director of Molecular Pathology Laboratory, Department of Pathology, Mount Sinai School of Medicine, New York, NY, USA

Shaobo Zhang, MD Associate Scientist, Department of Pathology and Laboratory Medicine, Indiana University School of Medicine, Indianapolis, IN, USA 